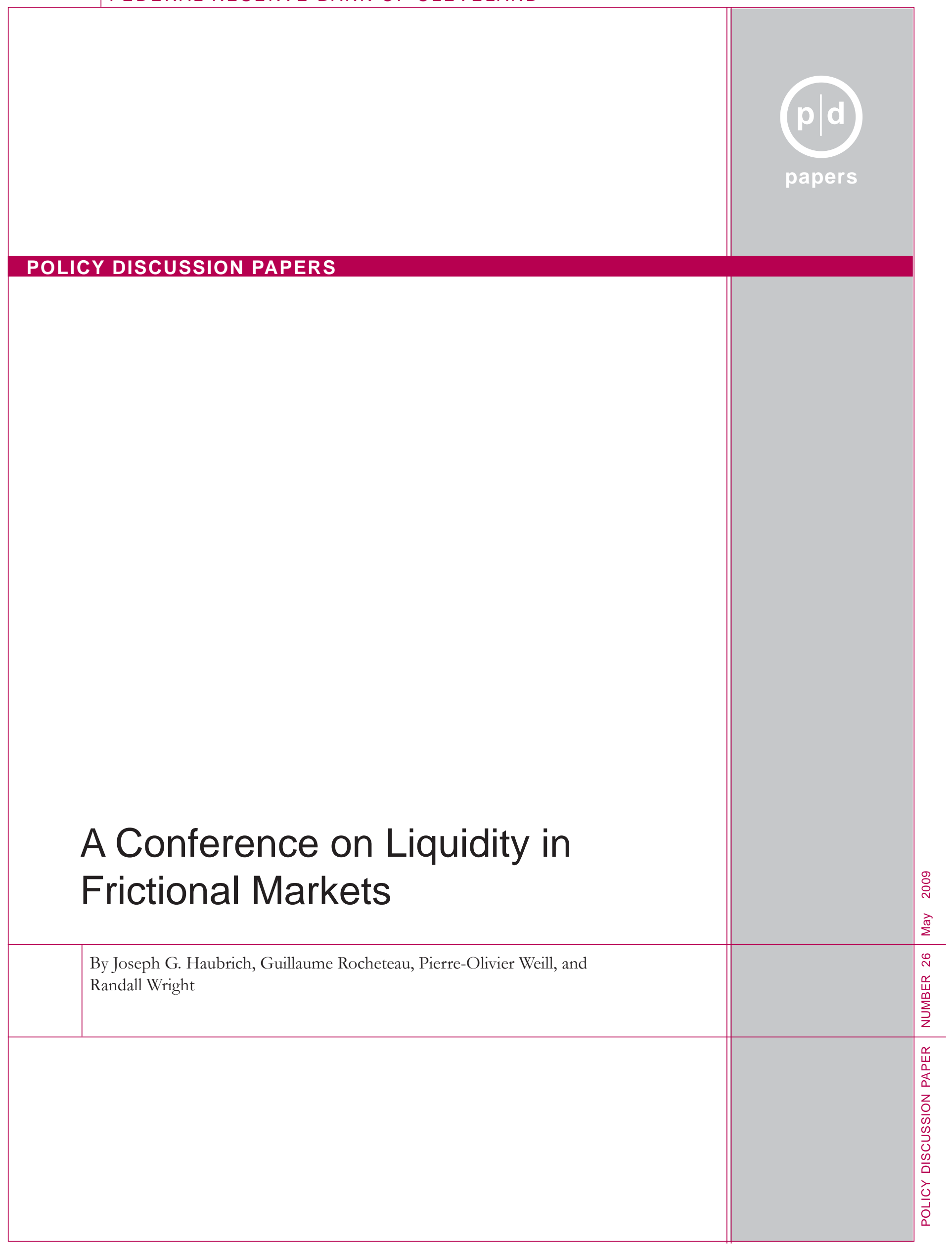




\section{A Conference on Liquidity in Frictional Markets}

By Joseph G. Haubrich, Guillaume Rocheteau, Pierre-Olivier Weill, and Randall Wright

This Policy Discussion Paper summarizes the papers that were presented at the Liquidity in Frictional Markets conference in November 2008. The papers, which looked at markets for assets as diverse as houses, bank loans, and electronic funds transfer, all explored that amorphous concept called "liquidity" and how its presence—or absenceaffects the economy.
Joseph G. Haubrich is vice president at the Federal Reserve Bank of Cleveland. Guillaume Rocheteau is associate professor of economics at the University of California at Irvine. Pierre-Olivier Weill is assistant professor of economics at the University of California, Los Angeles. Randall Wright is the James Kim Professor of Economics at the University of Pennsylvania.

Materials may be reprinted, provided that the source is credited. Please send copies of reprinted materials to the editor.

Policy Discussion Papers are published by the Research Department of the Federal Reserve Bank of Cleveland. To receive copies or to be placed on the mailing list, e-mail your request to 4dsubscriptions@clev.frb.org or fax it to 216-579-3050. Please send your questions comments, and ISSN 1528-4344 suggestions to us at editor@clev.frb.org.

Policy Discussion Papers are available on the Cleveland Fed's site on the World Wide Web: www. clevelandfed.org/Research.

Views stated in Policy Discussion Papers are those of the authors and not necessarily those of the Federal Reserve Bank of Cleveland or of the Board of Governors of the Federal Reserve System. 


\section{Introduction}

On November 14-15, 2008, a group of distinguished scholars met in the conference room of the Federal Reserve Bank of Cleveland's Learning Center and Money Museum to discuss issues relating to "Liquidity in Frictional Markets." The conference was cosponsored by the Journal of Money, Credit, and Banking. The papers, which looked at markets for assets as diverse as houses, bank loans, and electronic funds transfer, all explored that amorphous concept called "liquidity" and how its presence — or absence — affects the economy. The papers also shared a methodological perspective, using search, network, and game theories as alternatives to Walrasian market clearing.

\section{Monetary Policy}

Three papers focused on monetary policy.

In "Elastic Money, Inflation, and Interest Rate Policy," Allen Head and Junfeng Qiu study optimal monetary policy in an environment in which money plays a basic role in facilitating exchange, while aggregate shocks affect households asymmetrically and exchange may be conducted using either bank deposits (inside money) or fiat currency (outside money). A central bank controls the stock of outside money in the long run and responds to shocks in the short run using an interest rate policy that manages private banks' creation of inside money and influences households' consumption. The zero bound on nominal interest rates prevents the central bank from achieving efficiency in all states. Long-run inflation can improve welfare by mitigating the effect of this bound.

In "Price-Level Targeting and Stabilization Policy" Aleksander Berentsen and Christopher Waller construct a dynamic stochastic general equilibrium model to study optimal monetary stabilization policy. Prices are fully flexible, and money is essential for trade. Their main result is that if the central bank pursues a price-level target, it can control inflation expectations and improve welfare by stabilizing short-run shocks to the economy. The optimal policy involves smoothing nominal interest rates, which effectively smoothes consumption across states.

Nicolas L. Jacquet and Serene Tan, in "Money, Bargaining, and Risk Sharing," investigate money's dual role as a self-insurance device and a means of payment, when perfect risk-sharing is not possible and the two roles of money are disentangled. They use a variant of Lagos and Wright's approach (2005), where agents face a risk in the centralized market as follows. In the decentralized market, the main role for money is as a means of payment, while in the centralized market it is a self-insurance device. The authors show that state-contingent inflation rates can improve agents' ability to self-insure in the centralized market, thereby improving the terms of trade in the decentralized market. The authors also characterize the optimal monetary policy. 
Payments Systems

Four papers focused on the payments system and the nuts and bolts of the monetary system.

In "Counterfeiting as Private Money in Mechanism Design," Ricardo Cavalcanti and Ed Nosal describe counterfeiting activity as the issuance of private money, one which is difficult to monitor. The approach, which amends the basic random-matching model of money in mechanism design, allows a tractable welfare analysis of currency competition. They show that it is not efficient to eliminate counterfeiting activity completely. They do this without appealing to lottery devices, and argue that this is consistent with imperfect monitoring.

Adam Ashcraft, James McAndrews, and David Skeie consider "Precautionary Reserves and the Interbank Market." Liquidity hoarding by banks and extreme volatility of the federal funds rate was widely seen as having severely disrupted the interbank market and the broader financial system during the 2007-08 financial crisis. Using a dataset of intraday Federal Reserve bank account balances and Fedwire interbank transactions, the authors estimate all overnight federal funds trades during this time period. They document the extreme federal funds rate volatility that occurred and provide empirical evidence on banks' precautionary hoarding of reserves and reluctance to lend. The authors then develop a model with credit and liquidity frictions in the interbank market consistent with the empirical results. Banks rationally hold excess reserves intraday and overnight as a precautionary measure to self-insure against liquidity shocks. The intraday fed funds rate sometimes spikes above the discount rate and falls near zero. Apparent anomalies during the crisis may be explained as the stark but natural outcomes of the authors' general model of the interbank market. The model also provides a unified explanation for previously documented stylized facts and makes new predictions for the interbank market.

In "Systemic Risk and Liquidity in Payment Systems," Gara M. Afonso and Hyun Song Shin study liquidity and systemic risk in high-value payment systems. Flows in such high-value systems are characterized by high velocity, meaning that the total amount paid and received is high relative to the stock of reserves. In such systems, banks rely heavily on incoming funds to finance outgoing payments, necessitating a high degree of coordination and synchronization. They use lattice-theoretic methods to solve for the unique fixed point of an equilibrium mapping and conduct comparative statics analyses on changes to the environment. Banks that attempt to conserve liquidity actually increase the demand for intraday credit and, ultimately, cause a disruption of payments. Additionally, when a bank is identified as vulnerable to failure and other banks cancel payments to that bank, there are systemic repercussions.

Ricardo Lagos formulates a search-based asset-pricing model in which both equity shares and fiat money can be used as means of payment in "Asset Prices, Liquidity, and Monetary Policy in an Exchange Economy." It is then possible for him to characterize a family of optimal stochastic monetary policies. Every policy in this family implements Friedman's prescription of zero nomi- 
a constant but nonzero nominal interest rate. Under such policies, the average real return on equity is negatively correlated with the average inflation rate.

\section{Trading Frictions in Asset Markets}

Four papers looked at trading frictions in asset markets, continuing an influential recent trend to use search models to examine market microstructure.

Like Lagos, Yong Kim, in "Liquidity and Selection in Asset Markets with Search Frictions," also looks at an asset market subject to search frictions, but one in which both asset liquidity and market composition are determined endogenously. The analysis predicts that higher asset prices resulting from exogenously higher asset earnings imply a:

- $\quad$ Shorter search duration for sellers (higher liquidity)

- $\quad$ Shorter owner tenure before listing assets for resale (turnover)

- Higher stock of buyers

- Higher share of the asset stock traded (trade volume)

Asset price-earnings ratios respond positively to earnings because liquidity premiums respond to the size of earnings relative to the costs of search. Kim shows that liquidity effects and selection effects reinforce each other in the presence of search frictions.

In "Liquidity Provision in Capacity-Constrained Markets" Pierre-Olivier Weill studies a competitive, dynamic financial market subject to a transient selling pressure, when market makers face a capacity constraint on the number of trades they can make with outside investors. This induces market makers to provide liquidity in order to manage their capacity constraint optimally over time: They use slack capacity early to accumulate assets when the selling pressure is strong, so as to relax their capacity constraint and sell to buyers more quickly when the selling pressure subsides. When the capacity constraint binds, the bid-ask spread is strictly positive, widening and narrowing as market makers build up and unwind their inventories. Since the equilibrium asset allocation is constrained Pareto optimal, the time variations in bid-ask spreads are not symptomatic of inefficient liquidity provision.

In “Trading Frictions and House Price Dynamics," Andrew Caplin and John Leahy construct a model capable of explaining much of the recent experience in the housing market. Their model of trade with matching frictions provides a simple characterization for the process through which sales and inventory determine housing prices. They then compare the implications of the model to certain properties of housing markets and find it can explain the large price changes and the positive correlation between house prices and sales found in the data. Unlike the data, prices are negatively autocorrelated, and high inventory predicts price appreciation. They also investigate several amendments to the model.

Christophe Chamley and Celine Rochon, in "When Banks Lend for too Long," explore a model of lending in which the decision between rolling over or terminating a loan is the result of a privately efficient debt contract under imperfect information. Loans are established in matches

\section{Liquidity Provision in Capacity-Constrained Markets}

Pierre-Olivier Weill

Trading Frictions and House Price Dynamics Andrew Caplin and John Leahy

When Banks Lend for Too Long

Christophe Chamley and Celine Rochon 
between banks (lenders) and entrepreneurs (borrowers), who meet in a search process. Projects randomly turn out a quick payout or a long-term payout that requires a rollover of the loan. The model generates, under proper parameter conditions, multiple steady states, and a small monitoring cost may generate a large macroeconomic effect. The model is simplified for the analysis of the dynamics. There is a continuum of cycles that are separated by crises, in which the stock of loans is reduced by a quantum amount of loan terminations.

Money, Liquidity, and Banks

Three papers explored the subtle relationships between money, liquidity, and banks.

"Information, Liquidity, and Asset Prices" by Benjamin Lester, Andrew Postlewaite, and Randall Wright studies how recognizability affects assets' acceptability, or liquidity. Some assets, like U.S. currency, are readily accepted because sellers can easily recognize their value, unlike stock certificates, bonds, or foreign currency. This idea is common in monetary economics, but previous models deliver equilibria where less-recognizable assets are always accepted with positive probability, never zero probability. This is inconvenient when prices are determined through bargaining, which is difficult with private information. These authors construct models in which agents outright reject assets that they cannot recognize, at least for some parameters. Thus, information frictions generate liquidity differences without overly complicating the analysis.

In "Uncertainty, Inflation, and Welfare," Jonathan Chiu and Miguel Molico use a microfounded search-theoretic monetary model to study the welfare costs and redistributive effects of inflation when there is idiosyncratic liquidity risk. They calibrate the model to match the empirical aggregate money demand and the distribution of money holdings across households, and study the effects of inflation under the implied degree of market incompleteness. In the presence of imperfect insurance, the estimated long-run welfare costs of inflation are on average 40 percent smaller than in a complete-markets, representative-agent economy. Furthermore, inflation induces important redistributive effects across households. For example, the welfare gains of reducing inflation from 10 percent to 0 percent is 0.59 percent of income. Moreover, the marginal redistributive effect of inflation is decreasing in the rate of inflation. They conclude that accounting for wealth effects is important for the measurement of the welfare costs of inflation, given that these effects are quantitatively significant.

Valerie R. Bencivenga and Gabriele Camera, in "Banks, Liquidity Insurance, and Interest on Reserves in a Matching Model of Money," introduce banks resembling those in Diamond and Dybvig (1983) into a model of money and capital based on Lagos and Wright (2005) and Aruoba and Wright (2003). Agents can self-insure against random liquidity needs by carrying money balances, but they can also withdraw money from their bank deposits, although there is a real resource cost of doing so. Banks create liquidity by pooling agents' savings and by holding a portfolio of primary assets (money and capital) that maximizes depositors' expected utility. From an agent's perspective, banks provide liquidity insurance; they reduce or eliminate unused money balances. In the aggregate, banks shift the composition of savings toward investment in physical

Information, Liquidity, and Asset Prices

Benjamin Lester, Andrew Postlewaite, and Randall Wright

Uncertainty, Inflation, and Welfare

Jonathan Chiu and Miguel Molico

Banks, Liquidity Insurance, and Interest on Reserves in a Matching Model of Money

Valerie R. Bencivenga and Gabriele Camera 
capital, which increases agents' rate of return on their savings. Thus, banks have the potential to improve welfare, despite their cost. When the withdrawal cost is sufficiently small, agents save only through deposits, and banks provide complete liquidity insurance (there are no unused money balances). When the cost is moderate, agents optimally combine self-insurance (agents carry some money) and liquidity insurance through banks (some agents make withdrawals, and banks hold reserves). The optimal contract has a nonlinear schedule of interest rates on deposits in this case. When the cost is large, liquidity insurance becomes prohibitively expensive, and banks cannot improve welfare. The threshold levels of the cost are increasing in the inflation rate. A policy of paying interest on reserves can reverse some or all of the distortionary effects of inflation, provided the withdrawal cost is sufficiently small, by inducing banks to offer specific incentivecompatible deposit contracts. Banks cannot observe agents' liquidity needs, and therefore deposit contracts cannot condition on them.

The conference covered a broad range of papers in terms of techniques used, questions addressed, and markets investigated. Perhaps the broad message of these papers is that a deeper understanding of market mechanisms and the frictions that lead to them can yield insights that are surprisingly relevant for policy questions. 


\section{References}

Diamond, Douglas W., and Philip Dybvig. 1983. "Bank Runs, Deposit Insurance, and Liquidity," Journal of Political Economy, vol. 91 pp. 401-19.

Aruoba, S. Boragan, and Randall W. Wright. 2003. "Search, Money, and Capital: A Neoclassical Dichotomy," Journal of Money Credit and Banking, 35(6), 1086-105.

Lagos, Ricardo, and Randall W. Wright, 2003. "A Unified Framework for Monetary Theory and Policy Analysis," Journal of Political Economy, vol. 113, pp. 463-84. 
Papers Presented at the Conference

Asset Prices, Liquidity, and Monetary Policy in an Exchange Economy

Ricardo Lagos

Banks, Liquidity Insurance, and Interest on Reserves in a Matching Model of Money

Valerie Bencivenga and Gabriele Camera

Counterfeiting as Private Money in Mechanism Design

Ricardo Cavalcanti and Ed Nosal

Federal Reserve Bank of Cleveland working paper, no. 07-16.

Elastic Money, Inflation, and Interest Rate Policy

Allen Head and Junfeng Qiu

Queen's University working paper, no. 1152.

Information, Liquidity and Asset Prices

Benjamin Lester, Andrew Postlewaite, and Randall Wright

University of Pennsylvania, Penn Institute for Economic Research

working paper, no. 08-039.

Liquidity and Selection in Asset Markets with Search Friction

Yong Kim

Liquidity Provision in Capacity Constrained Markets

Pierre-Olivier Weill

Money, Bargaining, and Risk Sharing

Nicolas Jacquet and Serene Tan

Precautionary Reserves and the Interbank Market

Adam Ashcraft, James McAndrews, and David Skeie

Price-Level Targeting and Stabilization Policy

Aleksander Berentsen and Christopher Waller

Systemic Risk and Liquidity in Payment Systems

Gara Minguez Afonso and Hyun Song Shin

Federal Reserve Bank of New York staff report, no. 352.

Trading Frictions and House Price Dynamics

Caplin, Andrew, and John Leahy

National Bureau of Economic Research working paper, no. 14605.

Uncertainty, Inflation, and Welfare

Jonathan Chiu and Miguel Molico

Bank of Canada working paper, no 3002-13.

When Banks Lend for Too Long

Christophe Chamley and Celine Rochon 


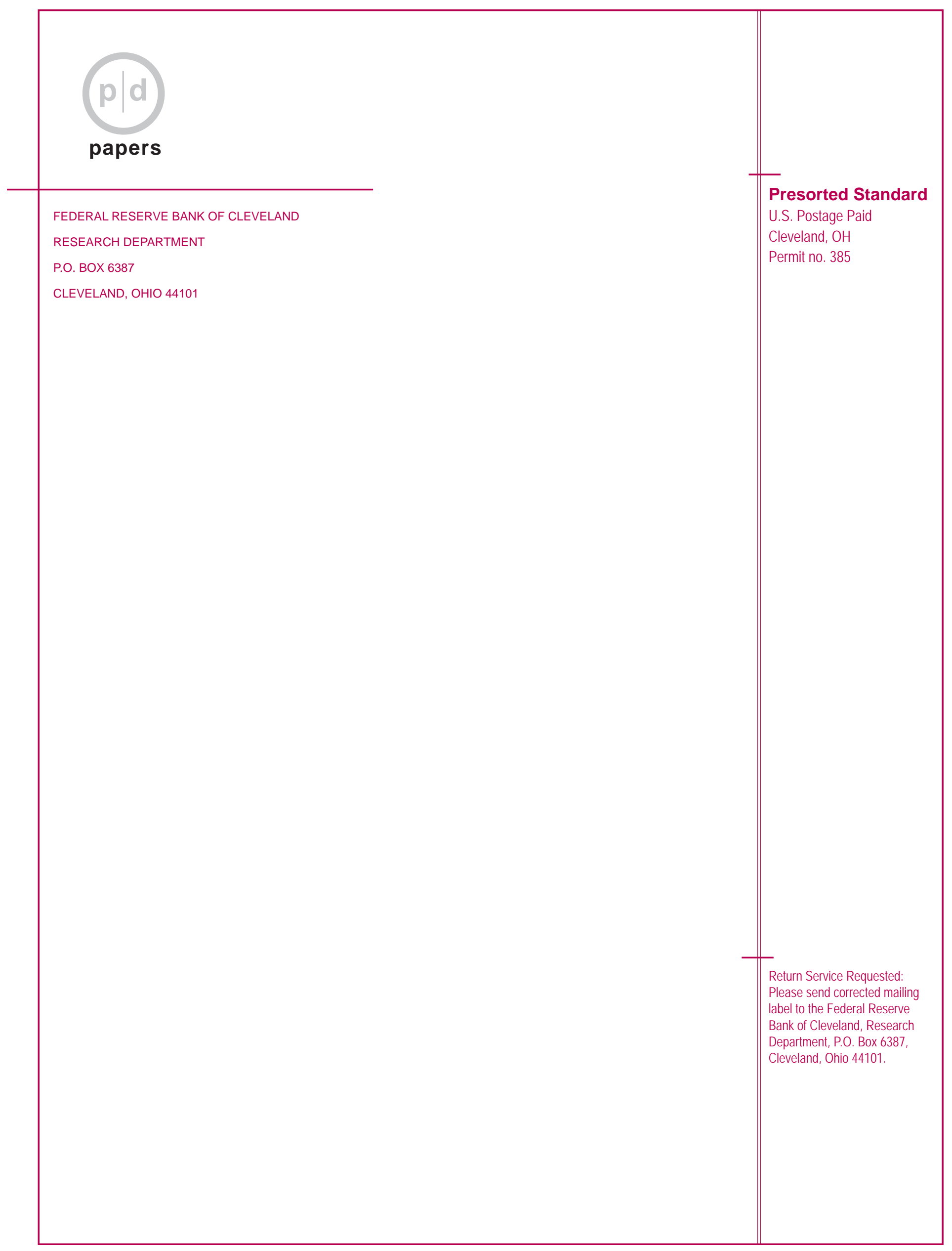

